\title{
The Development and Application of Power System Relay Protection Technology
}

\author{
Zhang He, Sun Lin, Zhang Jing, Zheng Deguo, Wang Liang, Weng Xiaoyu, \\ Jiang Jun
}

Panjin Power Supply Company, Liaoning Electric Power Company Limited, State Grid, China, 16295036@qq.com

Keywords: relay protection, intelligent, network, automation

\begin{abstract}
This article mainly tells the development of power system relay protection technology, application status and application prospect in the future, and for the relay protection device equipment type selection, function analysis, this paper introduces the current mainstream of relay protection technology, at the same time on the future development trend of relay protection device, this paper hopes to sprang out.

With the rapid development of economy, all walks of life make higher requirement to the relay protection technology, especially in power system. If you want to do a good job in the application of relay protection technology, the first thing to know is the development process. Firstly this article introduces the general course of development,secondly focus on the basis of the current application protection technology which are introduced, and finally puts forward the development direction of power system relay protection technology.
\end{abstract}

\section{The development of power system relay protection technology}

Only enough understanding to electric power system relay protection technology development history of can better make the application of modern power system relay protection technology and improve their work. In the sixties and seventies of the 20th century our country began the application of power system relay protection technology, initially it was transistor relay protector. Then the integrated circuit protection device based on the integrated operational amplifier gradually replaced the transistor relay protector. With the development of science and technology, the microcomputer relay protector has been vigorously promoted. From the development of power system relay protection technology,you can see that the application and development of modern electric power system relay protection technology is heading for the network and electronic.

\section{The application of power system relay protection technology}

\section{Choose device type according to actual situation}

Power system relay protection devices are determined according to the actual demand of power system equipment type.And the basic of doing well in relay protection technology is to choose equipment according to the actual situation.

First of all, the demand for electric power system relay protection device is the most basic is to work smoothly, successfully completed on the system running status monitoring, automatic removal of electric power system fault etc.Second, due to the rapid development of modern network monitoring technology, and has been widely used in the relay protection device, which requires the relay protection device can in coordination with the network monitoring system, achieve the power system automation and network monitoring have put forward specific requirements. Therefore, in the choice of modern electric power system relay protection device type, we will strictly according to the need of the power system relay protection function to choose the right equipment to do a good job of relay protection smoothly. Besides we should give full consideration to equipment and devices of mobility, security, stability, etc. 


\section{Application analysis of power system relay protection function}

Protection to the relay protection device of capacitor protection, main transformer protection, bus coupler protection and line protection, and other functions are widely used in the application of power system.Application of these functions, can be effective for power system in the process of power transmission and transformation equipment protection, so as to avoid the occurrence of the fault and save money.

The analysis of the network under the background of relay protection technology application

The rapid development of modern automation technology, The combination of the modern automation technology and apply,such as widely used in power system relay protection technology in the network, computer science and technology, such as integrated automation. make modern electric power system relay protection device is more intelligent and networked.

First of all, the application of single-chip computer technology in power system relay protection, computerization, the relay protection up to relay protection device provides more precise and flexible operation. Second, computer technology and network technology in the wide application of relay protection device, make the relay protection work more networking and information.In accelerating the speed of data processing at the same time effectively to achieve the remote fault the purpose of on-line monitor and alarm, etc.In addition, the network technology, the integrated use of computer technology, communication technology, in the center of the power system relay protection devices and to establish a close relationship between the monitoring system, save the related staff to monitor, adjust the steps, make work more intelligent.

In recent years, in order to meet the demand of the intelligent power system relay protection, using science in relay protection network structure to monitor relay protection is conducive to the safe and stable operation of power system.Single chip computer technology, computer technology, network technology and intelligent technology of comprehensive use of modern power system relay protection device and integrated with the power transmission and transformation, effectively guarantee the safe and stable operation of power system of power transmission and transformation.

\section{The development direction of power system relay protection technology in the future}

The rapid development of science and technology, makes the modern electric power system relay protection technology in the network, intelligent, computerization and the direction of integration, we will be taken from the three aspects specific analysis of the development trend of relay protection technology below.

\section{Intelligent network}

The rapid development of science and technology makes the power system more intelligent. Neural networks, fuzzy logic, genetic algorithm in the whole power system has been widely used. We begin to use these techniques In the aspect of relay protection.As one of the nonlinear mapping method of neural network technology,it can effectively calculate the complicated nonlinear problem and difficult equation, make the job easier.Reasonable combination of the intelligent method can speed up the processing speed and makes complex problem simple. Intelligent network in the application of relay protection, for the development of relay protection work provides a new train of thought, can better to do a good job of relay protection.

\section{The adaptive control technology will be widely used}

The idea of adaptive relay protection began in the $1980 \mathrm{~s}$ or so, it can monitor the operation condition of power system on time,adjust the setting value, performance and characteristics according to the change of operation condition, and the faults in the operation, so as to achieve the purpose of protection. When the frequency, oscillation in power system changes or single-phase grounding short circuit transition resistance abnormal to other problems, using the adaptive control technology, can quickly and efficiently to provide the corresponding protection. Principle of adaptive relay protection for power system changes,protect the performance of relay protection at the maximum this new relay protection technology has received the widespread attention and enhance the vitality of the microcomputer protection.Adaptive relay protection become more 
reliable, which can effectively improve the system response time, widely used in the distance of the transmission lines, transformers, generators, such as automatic reclosing protection work, etc.Although the start time of adaptive protection technology is early and it still have lots of space to improve, it has achieved good results now.But if you want to achieve true adaptive, we still have a long way to go, requires us to collect the information of system failure and run the relevant more comprehensive, do a good job of information collection and analysis, and do a good job of protection related intelligent and networked.

\section{Modern computer science and technology will get to popularize and apply}

We need to conduct a comprehensive technical innovation for system integration technology of high pressure and the basis of the substation, in order to change the current transformer substation monitoring, protection, measurement and control device and the system state of segmentation completely,so that we can establish a close contact between the integrated automation technology and relay protection device, and meet the needs of remote control with information sharing and integration with resource sharing better.Its core is that the microcomputer protection device, the distance of the terminal unit (RTU), substation measurement adding at the computer system, signal, control, charging circuit, which replaces the original relay control protection screen .At the same time it can reduce the equipment investment, save occupied area, make the system more stable and reliable.At present, in order to do a good job control and protection and measurement better, we will all outdoor substation equipment through the control cables,such as transformer, line voltage, secondary current connection to the master control room.we need to invest a lot of money and a lot of manpower, in addition that the second circuit is complicated when laying cable.At the same time, if we install control, measure and protection, data communication integration of computer near the substation which need to be protected outdoor,transform digital power flow and voltage of the protected equipment and send them to the main control room through the computer network technology so that you can effectively reduce the capital investment in terms of cable, the transmission quality will be improved at the same time, and it can effectively avoid the impact of electromagnetic signals.

\section{Conclusion}

This article introduce the electric power system relay protection technology in the development of the process at first, then discuss the application of the relay protection technology in detail.finally points out the development direction of power system relay protection technology in the future.Designed to help related department to do a good job in the application of relay protection technology defined the direction of its future development, relevant staff better completes the labor of duty.Because of my limited ability, the research of this aspect is still inadequate, but believe that through the joint efforts of more professional,it will be a better application of relay protection technology, so that the power system will be continuous and stable operation ,make greater contribution for production and living of social economic development.

\section{References}

[1] Chen Liyi, GuQiang. Digital Simulation and its Development in Power System[J]. Automation of Electric Power Systems, 1999, 23 (23): 1-6

[2] Huang Jiayu, Chen Liyi, Sun Dechang. Digital Simulation of Power System[J]. Beijing: China Water Power Press, 1995

[3] Jing Yinpo. The simulation training system of $110 \mathrm{kV}$ unmanned substation and control center Sichuan electric power technology, 1999, (2): $56 \sim 60$

[4] Gao Ze'e, You Zhaojin. The simulation training system of Dagang oilfield substation [J]. Petroleum planning and design.1998, (6): $38 \sim 38$

[5] Zhang Dongying, Liu Dao, Zhou Qingjie. The simulation and training system based on the microcomputer network of substation[J]. North China electric power, 1998, (2): $66 \sim 68$ 